\title{
The use of the construction with a digital camera and GPS receiver while researching dangerous areas
}

\author{
Oleksandr Dolgikh ${ }^{1, *}$, Liubov Dolgikh ${ }^{1}$, Kostiantyn Ielezov ${ }^{2}$, and Nikolai Maletskii ${ }^{3}$ \\ ${ }^{1}$ Kryvyi Rih National University, Department of Mine Surveying, 11 Matusevycha Ave., Kryvyi Rih, 50027, Ukraine \\ ${ }^{2}$ ROOSSLER engineering surveying GmbH GEON group of companies, Wiesestraße 6, D-07548 Gera, Germany \\ ${ }^{3}$ Belaruskali, Korzha 5, Soligorsk, Respublika Belarus
}

\begin{abstract}
The purpose of the study is to select an effective methods and equipment for observing deformations in dangerous areas of the terrain, such as areas that are undermined by underground mining. It is known that the topical task of the mine surveying service is to improve remote sensing methods for the state of movement zones with craters, dips, cracks. The research methodology is based on the results of the performed analysis of methods for observing deformations using modern devices and technologies, and experimental work using the developed methodology, which provides for the combined use of digital methods and GPS technologies. Experimental work was carried out at the facilities of the Ordzhonikidze mine using various remote sensing methods, including those developed by the authors. The research used a design consisting of a digital camera and a GPS receiver. The performed analysis of the obtained survey results, using the proposed design of two devices, has shown its effectiveness in remote methods of observing the objects deformations located in areas undermined by mining operations. The scientific novelty of the results obtained lies in the methods development for remote observation of deformations of the ground's surface and objects, based on the structure use from a digital camera and a GPS receiver. This method was developed to increase the efficiency of performing research on objects deformations located in places that are dangerous for finding a person. The efficiency of using terrestrial digital stereo survey when the coordinates of the photographing points are determined with the help of GPS has been proved. The practical significance of the study lies in increasing work efficiency the on monitoring deformations of the earth's surface, buildings and structures located in areas dangerous for field work by traditional methods, which are performed using leveling and measuring the distances between the benchmarks of profile lines, which are usually used on areas undermined by underground mining. The use of terrestrial digital stereo photography with the coordination of photographing stations using GPS allows remote determination of the spatial position of the observed points with the required accuracy. Key words: ground stereoscopic survey, collapse zone, digital camera, GPS.
\end{abstract}

\section{Introduction}

When developing a mineral, a large range of works is envisaged, which also includes the study of the properties of the mineral, the study of the stress-strain state of the field massif and other measures that ensure the most complete and efficient extraction of the mineral with the least losses for the environment [1-8]. However, when mining a mineral, both open and underground, there is a violation of the ecological balance and damage to the environment. As a result of the activities of the mining enterprises, the atmosphere is polluted and the fertile layer is disturbed. As a result, zones with craters, dips and cracks, etc. are formed on the ground's surface. All these negative manifestations are observed by mine surveyors and surveyors in order to take timely measures to reduce their harmful effects on industrial and residential facilities, as well as to protect the environment [9-12].

Therefore, when developing minerals, one cannot do without competent mine surveying. The mine surveying service provides all the work on the extraction of minerals, develops measures for the rational use of subsoil and land, and performs work on the observation of the rocks movement and the ground's surface [13-16].

Ukrainian and foreign scientists are engaged in the development of more efficient systems for the development of minerals and methods of mine surveying support, including measures for their safe production.

An important type of mine surveying, from the entire complex, is mine surveying, the results of which are used to solve many problems. The introduction of modern instruments for their implementation, as well as digital technologies for obtaining and processing data, contributes to the improvement of mine surveying. Many works are devoted to the introduction of photogrammetric methods of shooting using digital cameras and unmanned aerial vehicles (UAV) [17-19]. These methods are effective when observing the state of objects located in areas where it is dangerous for finding a person. Such work is carried out for various similar objects, including for the objects of

\footnotetext{
* Corresponding author: $\underline{\text { dlavgeod@gmail.com }}$
} 
mining enterprises, where deformation processes are observed.

When choosing a surveying camera and an aircraft, they are guided by the requirements for the accuracy of solving a particular problem. It is known that the accuracy of a document created from the results of a digital survey carried out with a UAV is influenced by the surveying parameters and the characteristics of the survey equipment. This work is devoted to the study of these questions.

\section{The use of software in photogramme- try}

The modern photogrammetric methods are characterized by a high level of automation. Most of the operations that were previously performed by highly skilled performers can be performed by ordinary operators [20-22]. In many cases, the operator does not even need special knowledge of photogrammetry, since special programs are used to perform the survey and process the obtained material. Almost all software tools use ready-made processing templates, for example, Pix4D has 3D Maps, 3D Models, Ag Multispectral templates. In turn, templates are divided into those that carry out processing with low requirements for detail and accuracy and those that allow processing with high values of detail and accuracy. Some templates are designed to process data from different thematic cameras Ag Modified Camera or Agrgb, Thermomap Camera, etc. Nowadays such works as orientation of images on special photogrammetric devices (mutual, external orientation), which required a high qualification of the performer, are no longer performed. Even the construction of phototriangulation, the creation of photocircuits is carried out using software products. When designing and performing aerial photography of an area or an object, a minimum of knowledge about longitudinal and transverse overlaps, camera resolution, etc. is required. Calculations for the design of the survey are carried out according to the program using a computer, taking into account all the necessary parameters of the camera and the requirements for the scale and accuracy of the document (plan or orthomosaic), which is created based on the results of the survey. The initial data is set by the operator. However, to perform some work, special knowledge and experience is still required, for example, when drawing up situational and topographic plans for complex objects, which are deep quarries, when it is necessary to correctly position the recognition signs, select shooting parameters, and show elements on the plan with the required accuracy career, not just horizontal lines [23,24].

As a result of the automation and computerization of most processes, some photogrammetric methods have changed significantly or disappeared altogether. First of all, this concerns the methods in which a lot of routine field and office work was used, and some methods have turned from high-precision to survey. In support of this, we can consider phototheodolite photography, which has now changed and uses handheld or tripod photography, and is used to create overview digital models and presentations, or is an addition to aerial photography from un- manned aerial vehicles (UAV). In programs such as Photomodeler or Agisoft Metashape, the operator can build a digital model in a conditional coordinate system from any images (images) that have overlapping. Nowadays, amateur 3D models of architectural monuments, museums and other objects are often used in everyday life, tourism, and other spheres. Nowadays, professional ground surveying is rarely used to solve high-precision tasks. A significant number of programs and software complexes have been developed for the widespread use of unmanned aerial vehicles and digital imaging technologies.

\section{The simultaneous surveying research}

Phototheodolite photography, in the form in which it was used earlier, was much more accurate than aerial photography. A number of factors contributed to this:

- high binding accuracy of photographing stations and images;

- close-up of the image;

- lack of "blurring" of the image;

- high resolution of photographic plates that were used for photographing;

- the presence of a reference device made it possible to orient the camera relative to the photographing basis.

With the use of modern technologies when performing field work, the first factor that concerns the binding of photographing stations still exists in the form of determining the point coordinates from which the survey is performed, using standard autonomous GPS devices that can be installed on shooting cameras (for example, on Canon EOS 6D camera), or using separate GPS modules that work through the camera's hot shoe, such as the GP-E2 receiver. GPS devices of this class do not have the ability to receive differential corrections.

As a result, the camera positioning accuracy is from 5 to 8 meters in the planned position, and up to 10 meters in height. In many cases, this accuracy is sufficient to create a 3D-scene of an object.

The lack of "blur" in the image is explained by a technological leap in the creation of high-quality digital matrices for cameras, automatically or in manual mode is corrected and corrected by raising the ISO speed. Nowadays, cameras with wide-angle lenses that are mounted on UAV have found widespread use. When using them, in contrast to the narrow-angle (long-focus) ones, the amount of "blur" is insignificant and is not a critical factor. Increasing the ISO speed contributes to the appearance of "noise", but this does not significantly affect the accuracy of measurements on the model, that is, this factor is not critical either.

It is known that phototheodolite photography differed from aerial photography in higher accuracy; this was facilitated by the availability of a reference device. In the implementation of modern digital photography, this factor, which made it possible to obtain a high accuracy of terrestrial phototheodolite photography, replaces the use of a large number of images, the use of reverse photogrammetric intersection and high accuracy of pattern recognition [25-27]. 
The presence of one control point allows you to replace the process of camera orientation relative to the baseline. Another reason for not using camera orientation is the inappropriateness of software for this type of surveying.

It is known that the initial deformations studies of mining facilities objects, it is necessary to begin with the reconnaissance process of the area. When examining an object, for example, a displacement zones, it is necessary to determine the deformation values, velocities, volumes of extinguished voids, identify areas for special attention, etc [28,29].

On the territory that is located in the zone of displacement from the work of the Ordzhonikidze mine, the previous study was based on the results of aerial photography using the Sensefly drone with the following shooting parameters:

- flight altitude $203 \mathrm{~m}$;

- coverage area $1.87 \mathrm{~km}^{2}$;

- shooting positions 844 .

A camera mounted on a drone has the following characteristics:

- focal length $\mathrm{f}=18.5 \mathrm{~mm}$;

- pixel size 3.91 x 3.91 microns;

- the number of pixels is 24 million;

- shooting resolution: $3.89 \mathrm{~cm} /$ pix.

In addition, 975134 tie points, 2582845 projections with a reprojection error were used: 0.391 pix.

When aerial photography of mining facilities objects with significant differences in altitude, such as open pits, multi-tiered dumps, sinkholes zones, recognition signs should be located on them much more often than on a flat territory. Therefore, it is necessary to mark points on areas dangerous for a person, which is undesirable. But when creating a network of identification marks, you can get rid of the need to mark points in dangerous places Today, finding a person in a dangerous place can be replaced by the use of remote sensing and coordination methods. For this, it is advisable to determine the point coordinates from a line of intersection, built from four fixed points, or to determine them using the "reflectorless" mode of electronic devices.

The authors investigated the influence of the location of identification marks on the determining accuracy the spatial coordinates of the studied points. In the first case, all identification marks were included in the processing (Fig. 1a), and in the second, only identification marks located along the outer contour of the site (Fig. $1 b$ ).

The deformation values in the displacement trough, which is formed from the influence of underground mining of the Ordzhonikidze mine, can have values from several centimeters to several tens of meters. Therefore, when exploring this dangerous territory, it can be divided into sections for which definitions can be used with varying accuracy.

If for a funnel with a depth of several tens of meters, in the center, the deformation values can be determined roughly, with an accuracy of $1 \mathrm{~m}$ to $1.5 \mathrm{~m}$, and then it is possible not to mark the points directly in the funnel. But if it is necessary to ensure the accuracy of determining the position of the points of 0.1-0.3 meters, then marking is mandatory.
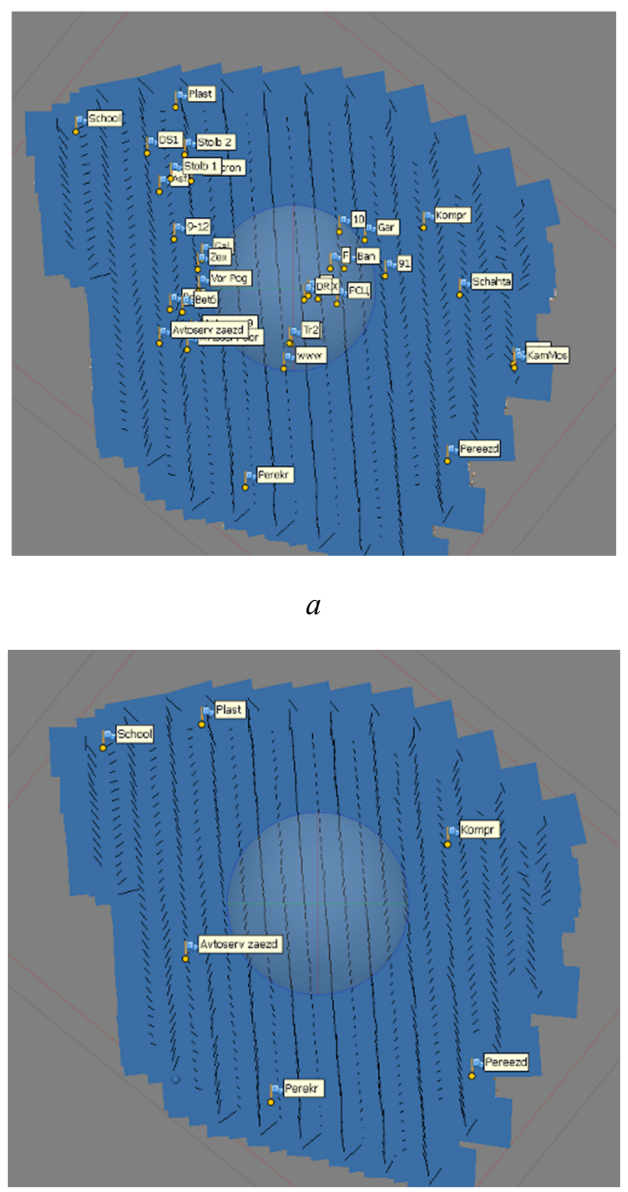

b

Fig. 1. Layout of identification marks: $a$ - over the entire area; $b$ - along the outer contour.

In fig. 2 shows a raster image of the funnel (Fig. 2a) and the distribution of errors in the values of deformations over the funnel field (Fig. $2 b$ ). The distribution of deformation values is shown in different colors, where they are more than 1.3 meters, they are indicated in red.

Root mean square errors on identification marks are shown in the graph (Fig. 3). The results of the analysis made it possible to exclude identification marks, the errors of which are more than 0.25 meters, from the use for orienting images.

\section{The joint use of a digital camera and a GNSS receiver}

The accuracy that aerial photography guarantees is sufficient for general surface monitoring, but for surfaces that have significant elevation differences, it gives large errors. Examples of such surfaces are the quarries sides, dumps and the surfaces of funnel-forming zones. To improve the observations accuracy of deformations, it is advisable to use ground stereotopographic survey.

It is shown in $[30,31]$ that it is expedient to study the areas deformations where the deformations are from 50 to $100 \mathrm{~mm}$ and more by the method of ground stereotopographic survey. But the method of ground stereotopographic survey considered earlier by the authors has a number of disadvantages, which consist in the mandatory 
presence of identification marks and in the need to fulfill the requirements their layout. Also, a significant drawback was the impossibility with the required accuracy to link the images in the areas dangerous for finding a person.

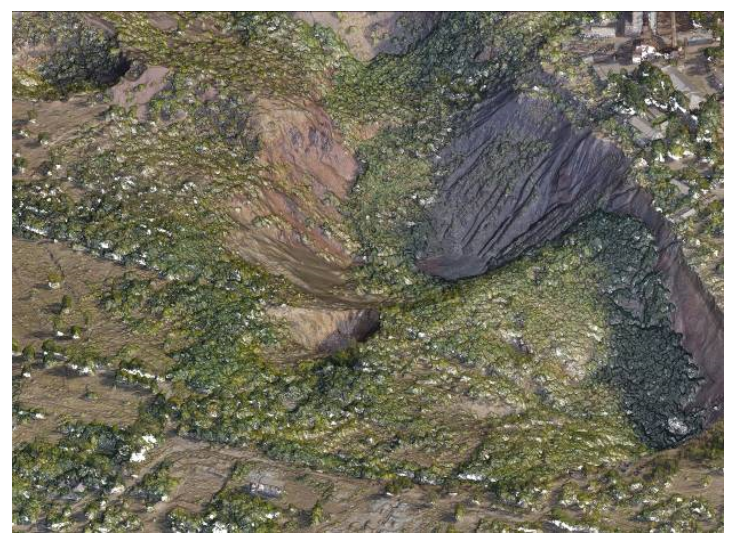

$a$

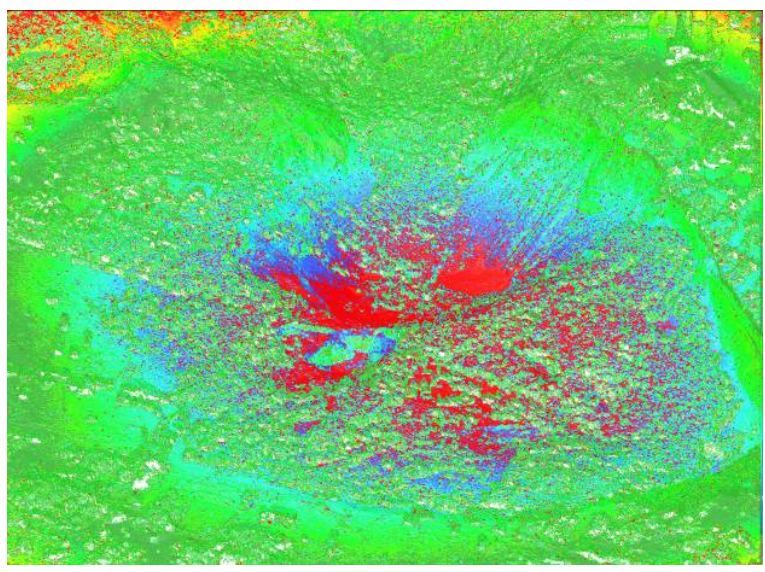

$b$

Fig. 2. Image of the funnel $(a)$ and the distribution of deformations $(b)$.

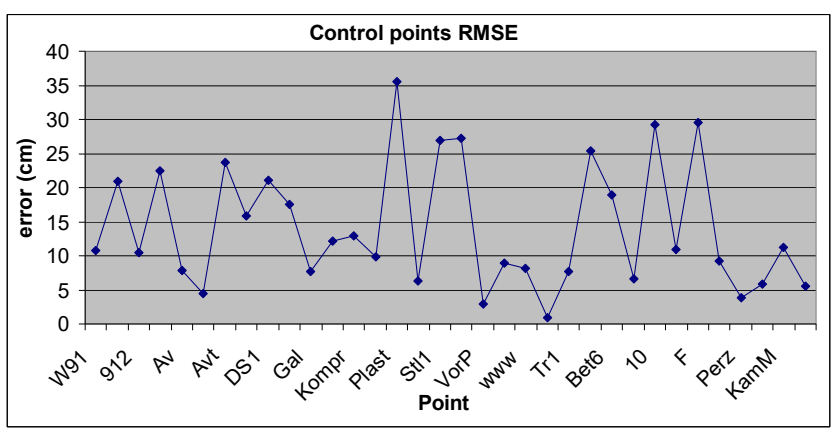

Fig. 3. Errors on identification marks.

When studying the deformations of quarry sides and dumps, as well as other mining enterprises objects, using ground digital survey, it became necessary to increase its accuracy [32]. For this, a design of the device was developed, which allows determining the coordinates of the photographing station with an accuracy of 5 to $15 \mathrm{~mm}$, depending on the observation time, PDOP and distance to the base.

The device is designed on the basis of a Canon EOS 750D digital camera and a Topcon HIPER Plus GNSS receiver (Fig. 4).

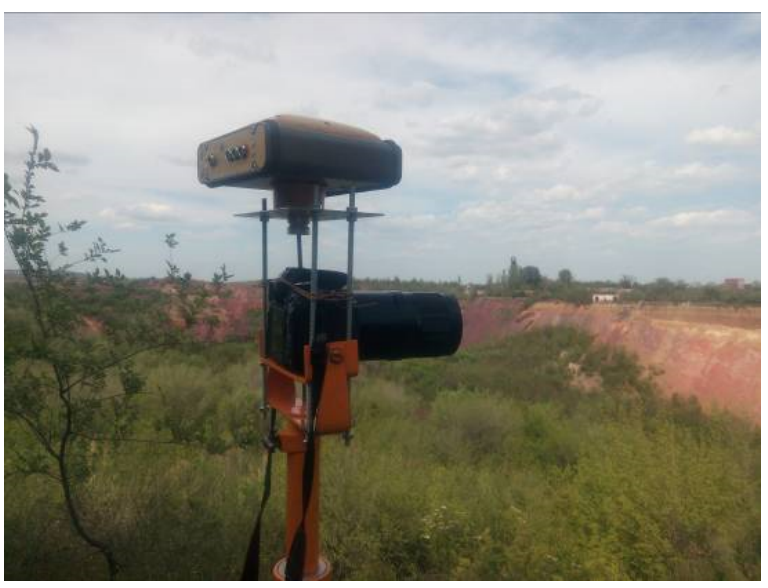

Fig. 4. Device design appearance, consisting of a digital camera and a GNSS receiver.

The design has an optical plummet (3), which is attached to a standard three-pin tribrach (1) through an adapter (2). Thanks to this, the adapter can be easily removed and an electronic total station is installed in its place. The GNSS receiver is attached with four pins (4) that allow you to adjust (decrease or increase) the distance to the camera. The hole in the plate (6) has a larger diameter than the bushing (5), which allow the GNSS receiver to be accurately centered over the camera (Fig. 5).

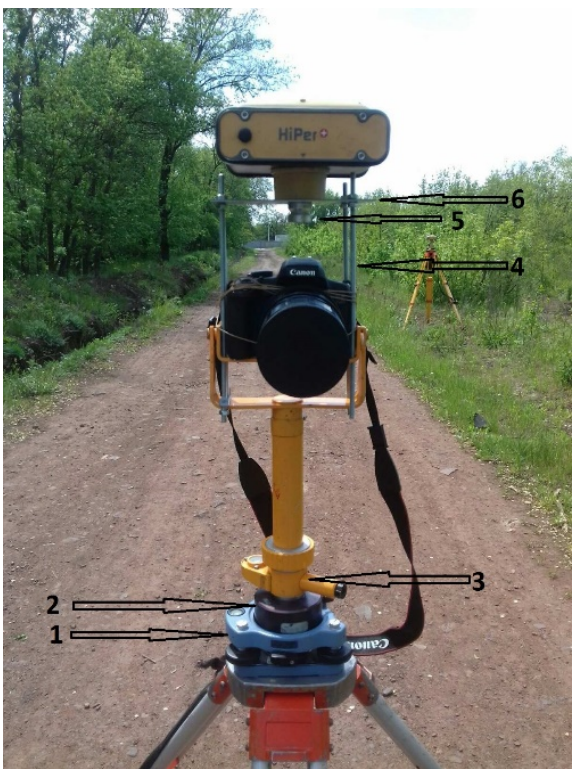

Fig. 5. Elements of the device.

With the help of this device, in May 2020, survey work was carried out from six stations, the distance between which was from 55 to 65 meters. The distance between the first and last photographing stations was 230 meters, and the distance to the base was approximately 200 meters (Fig. 6). 


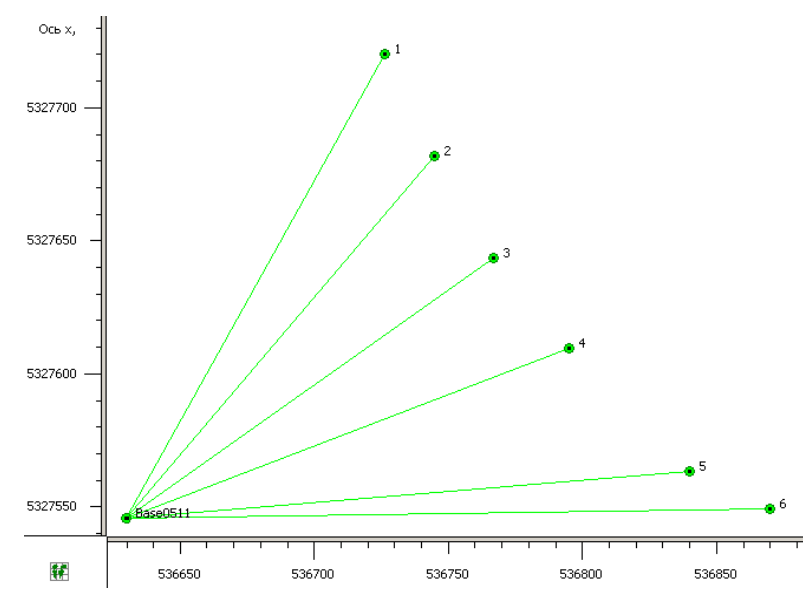

Fig. 6. Location of photographing stations and bases.

The studies were carried out on the territory, which is characterized as a zone of funnel formation from the activities of the Ordzhonikidze mine Central GOK. There are many mined out space in the mine take boundary; therefore the surface and subsoil are in a constant dynamic process. The speed of deformation processes on the day surface depends on the location in the depths of the areas with intensive mining works; therefore, work on predicting its further state is complicated by the fact that the mine is working.

To increase the accuracy of the survey results using device structure appliances, the survey parameters were pre-selected and the elements of the internal orientation of the camera were investigated, the accuracy of which significantly affects the accuracy of determining the position of survey points.

When using modern software for processing photographs (images) with standard settings, the focal length mode "Approximate" is used and the approximate focal length of the camera is taken. After adjustment, this value changes, and for each image its own focal length value is obtained. This also applies to other elements of interior orientation (distortion, main point coordinates). In addition, for each photographing station, coordinates $\mathrm{X}, \mathrm{Y}$ and
$\mathrm{Z}$ are determined, which characterize its spatial position. Approximate mode is used for most landmark surveys.

When the position of the photographing point is known with sufficient accuracy, the "Fixed" focal length setting mode is usually used.

In this case, the focal length was determined by photographing the KL-1000 reference ruler and determining the distance to the object using a Sokkia SET630R electronic total station. The defined focal length was 785.521 $\mathrm{mm}$.

Also, in the process of calibrating the camera, the dimensions of the matrix of the Canon EOS750D camera were refined, which amounted to $22.657 \mathrm{~mm} \times 15.104$ $\mathrm{mm}$.

The work investigates the research results of the influence of the determination accuracy of the focal length of a professional digital camera on the determination accuracy of the single point positions (Fig. 7) and their mutual position (Fig. 8) according to the digital model obtained from the survey results. In this case, the surveying was carried out without the use of recognition signs.

If, during surveying, the coordinates of the photographing station position are determined with an accuracy of $5 \mathrm{~mm}$, and the focal length is determined with an error of $1 \mathrm{~mm}$, then one can expect an error in determining the position of the studied points in the range from $0.7 \mathrm{~m}$ to $0.9 \mathrm{~m}$.

With a rough determination of the coordinates of the photographing station position, for example, with an accuracy of $5 \mathrm{~m}$, and with an error of $1 \mathrm{~mm}$ in the value of the focal length, the error in determining the position of the studied points can range from several to tens of meters.

\section{Conclusion}

The proposed method for performing ground-based digital surveys, with the coordination of photographing stations, using a GPS receiver installed on them, makes it possible to increase the efficiency of monitoring the objects deformations located in dangerous zones of rock movement and the ground's surface.

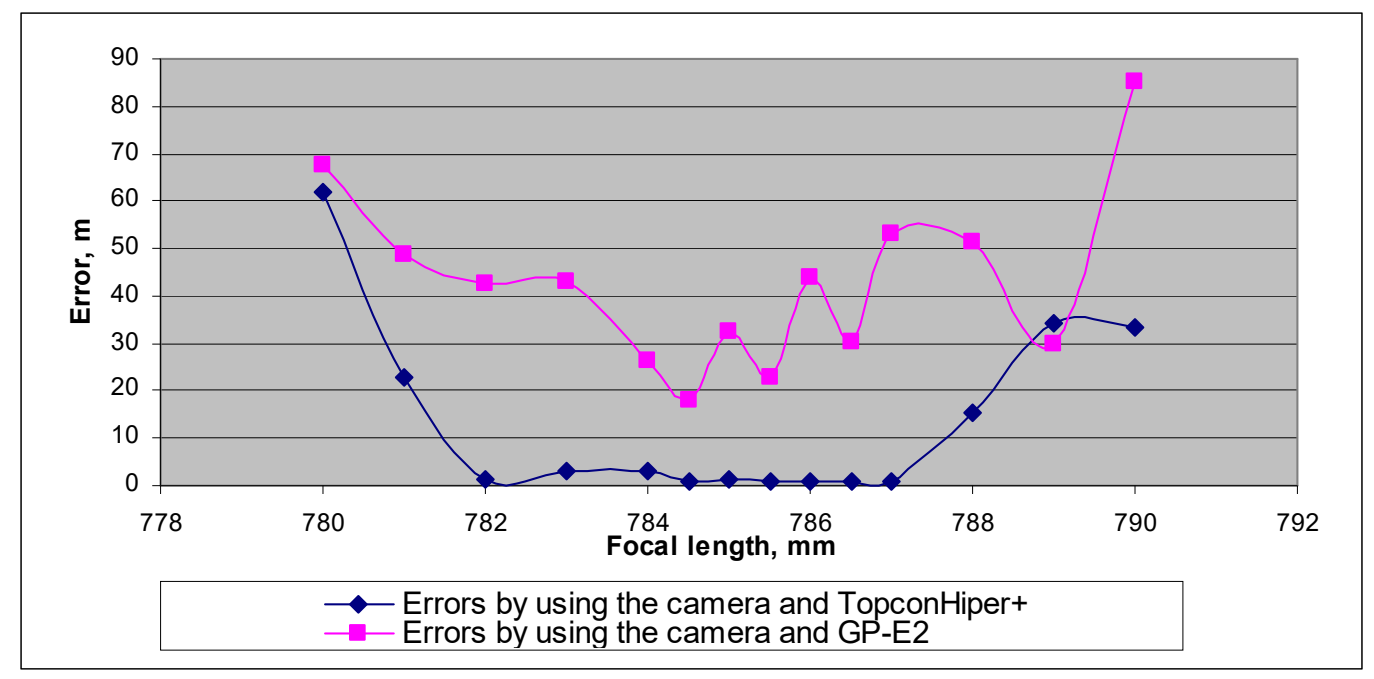

Fig. 7. Dependence of the accuracy of determining the position of points on the accuracy of the focal length. 


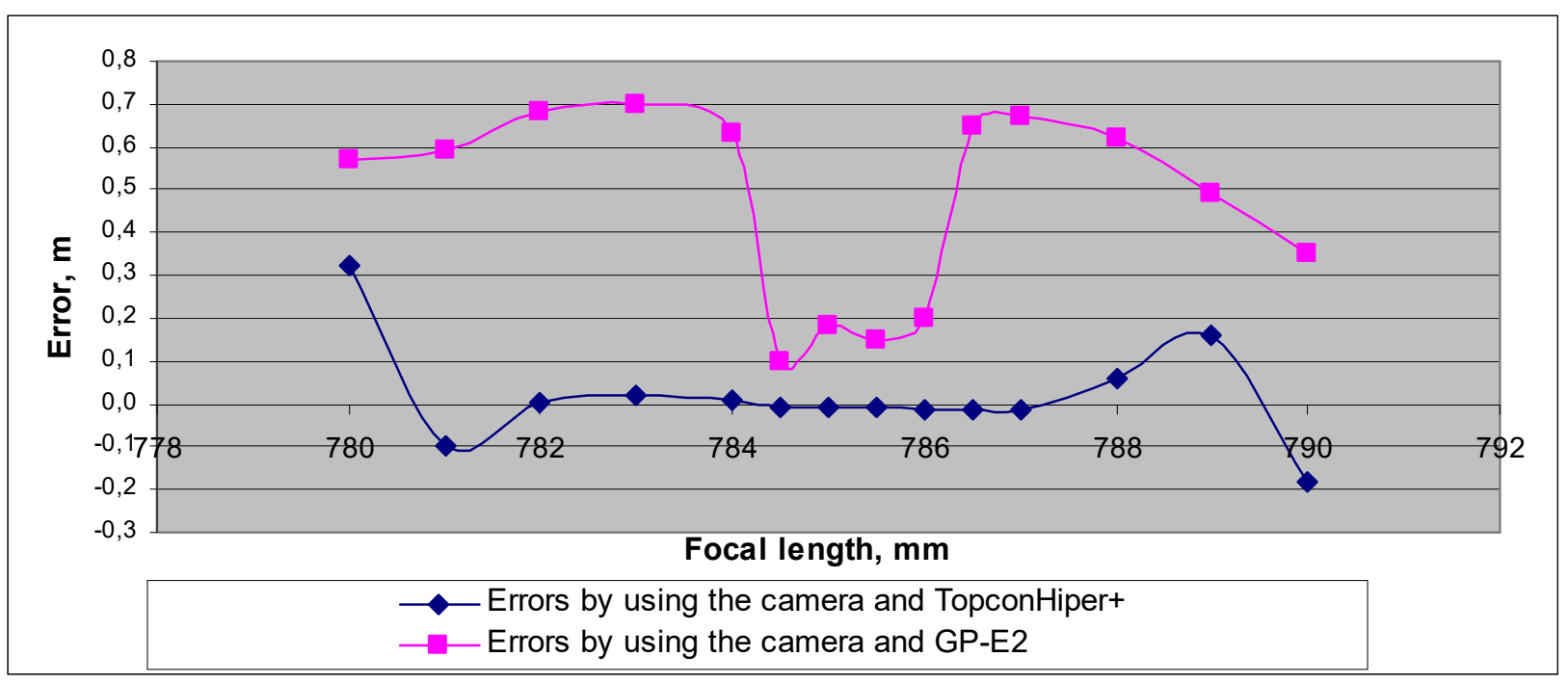

Fig. 8. Dependence of the accuracy of determining the relative position of points on the accuracy of the focal length.

At the same time, the accuracy of determining the coordinates of the studied points, without the use of identification marks, which are necessary for orienting images, increases 10 times or more. It is clear that the proposed technique will also improve the accuracy of work in which identification marks are used to orient the images. But such studies have not yet been carried out by the authors.

The authors are grateful to the administration of the PRIVATE JOINT STOCK COMPANY "CENTRAL IRON ORE ENRICHMENT WORKS" for the opportunity to carry out the research at its objects.

\section{References}

1. M.I. Stupnik, V.O. Kalinichenko, O.V. Kalinichenko, I.O. Muzika, M.B. Fed'ko, S.V. Pismennyi, Metallurgical and mining industry 7, 377-383 (2015)

2. M. Stupnik, V Kalinichenko, S. Pysmennyi, O. Kalinichenko, M. Fedko, MMD 10(3), 46-51 (2016). doi:10.15407/mining10.03.046.

3. S. Pysmennyi, M. Fedko, N. Shvaher, S. Chukharev, E3S Web of Conferences, 201, 01022. doi:10.1051/e3sconf/202020101022

4. M.B. Fedko, V.A. Kolosov, S.V. Pismennyy, Ye.A. Kalinichenko, Nauk. Visnyk Natsional. Hirnych. Univ., 4, 79-84 (2014)

5. V. Lozynskyi, P. Saik, M. Petlovanyi, K. Sai, Z. Malanchuk, Int. J. of Engineering Research in Africa, 35, $77-88$

(2018). doi:10.4028/www.scientific.net/jera.35.77

6. N. Shvaher, T. Komisarenko, S. Chukharev, S. Panova, E3S Web of Conferences, 123, 01043 (2019). doi:10.1051/e3sconf/201912301043

7. V. Peregudov, I. Hryhoriev, S. Joukov, Y. Hryhoriev, E3S Web of Conferences, 166, 02004 (2020). doi:10.1051/e3sconf/202016602004
8. S. Joukov, S. Lutsenko, Y. Hryhoriev, M. Martyniuk, V. Peregudov, E3S Web of Conferences, 166, 02005 (2020). doi:10.1051/e3sconf/202016602005

9. G. Firpo, R. Salvini, M. Francioni, P.G. Ranjith, Int. J. Rock Mech. Min. Sci. 48, 1045-1054 (2011)

10. D.J. Hutchinson, M. Lato, D. Gauthier, Proc. GEOQuebec, Quebec city, (2015)

11. C.M. Yeum, S.J. Dyke, Computer-Aided Civil and Infrastructure Engineering, 30(10), 759-770 (2015). doi:10.1111/mice.12141

12. F. Bardi, W. Frodella, A. Ciampalini, S. Bianchini, C. Del Ventisette, G. Gigli, R. Fanti, S. Moretti, G. Basile, N. Casagli, Geomorphology 223, 45-60 (2014). doi:10.1016/j.geomorph.2014.06.025

13. T. Carlà, P. Farina, E. Intrieri, H. Ketizmen, N. Casagli, Eng. Geol. 235, 39-52 (2018). doi:10.1016/j.enggeo.2018.01.021

14. Z.W. Wang, S. Yu, Q. Tao, G. Liu, H. Hao, K. Wang, C. Zhou, Int. J. Remote Sens. 39, 1199-1219 (2018). doi:10.1080/01431161.2017.1399473

15. J. Goetz, A. Brenning, M. Marcer, X. Bodin, RSE 210(208) (2018). doi:10.1016/j.rse.2018.03.013

16. E.S. Schultz-Fellenz, R.T. Coppersmith, A.J. Sussman, E.M. Swanson, J.A. Cooley, Pure Appl. Geophys. $175 \quad$ (9), 3159-3177 (2018). doi:10.1007/s00024-017-1649-0

17. J.V. Henrickson, C. Rogers, H.H. Lu, J. Valasek, Y. Shi, ICUAS 2016, 933-942 (2016). doi:10.1109/ICUAS.2016.7502

18. A.S. Essin, S.S. Essin, Interekspo GEO-Sibir', 1(4), 80-82 (2010)

19. D. Beregovoi, Montanuniversität Leoben department of mineral resources engineering (2015)

20. D. Fritsch, Photogrammetric Week '15, Ed. D. Fritsch, Wichmann, Berlin/Offenbach, pp. 3-20 (2015) 
21. M. Pollefeys, Visual 3D Modeling from Images (University of North Carolina, 2002), pp. 55-65 https://www.cs.unc.edu/ marc/tutorial.pdf.

22. F. Nex, F. Remondino. Applied Geomatics 6(1), 1-15 (2013)

23. F. Carvajal, F. Agüera, M. Pérez, ISPRS XXXVIII1/C22, 201-206 (2011)

24. V. Peterman, ISPRS, XL-1/W4, 215-218 (2015)

25. E.J. Lee, S.Y. Shin, B.C. Ko, C. Chang, Infrared Phys. Technol. 78, 223-232 (2016)

26. J. Suh, Y. Choi, Environ. (Earth Sci. 2017), p. 76

27. R.N. Nof, G. Baer, A. Ziv, E. Raz, S. Atzori, S. Salvi, Geology 41, 1019-1022 (2013)

28. A. Lucieer, S.M. de Jong, D. Turner, Prog. Phys. Geogr, 2013, doi: 10.1177/0309133313515293

29. Trubina L. K., Khlebnikova T. A., Nikolaeva O. N. JASR, 5(10) 482-488 (2015)

30. O. Dolgikh, L. Dolgikh, E3S Web of Conferences 166, $03002 \quad$ (2020). doi:10.1051/e3sconf/202016603002

31. O. Dolgikh, L. Dolgikh, I. Kuchnerov, E3S Web of Conferences 201, $01029 \quad$ (2020). doi:10.1051/e3sconf/202020101029

32. V. Kalinichenko, O. Dolgikh, L. Dolgikh, S. Pysmennyi, MMD, 14(4), 31-39 (2020). doi:10.33271/mining 14.04.031 